\title{
UMA POSSÍVEL PRECARIZAÇÃO DOS DIREITOS TRABALHISTAS, SOB A ÓTICA DO ADVOGADO ASSOCIADO, NOS LIMITES DA SECCIONAL DA BAHIA.
}

\author{
Rafael Ribeiro Santos* \\ Eric Araújo Andrade Oliveira*
}

\begin{abstract}
RESUMO:
O presente estudo utiliza como alicerce fundamentador uma pesquisa feita pela comissão especial dos advogados/as associados da seção do Estado da Bahia. Serão analisados também se os instrumentos jurídicos que regulamentam a tipologia jurídica do contrato de associação são respeitados, se os advogados entrevistados sofrem subordinação, se recebem de acordo com a efetiva partilha de resultados, se a carga horaria laboral máxima explicitada pela constituição é respeitada e se recebem contraprestação remuneratória condizente com o exercício profissional. Adotou-se, como método de pesquisa o dedutivo e a leitura qualitativa através da pesquisa: "relatório da comissão especial dos advogados/as associados".

Palavras-Chave: Vulnerabilidade; Proteção; Direito do Trabalho; Advogado Associado; Precarização.

\section{A POSSIBLE IMPAIRMENT OF LABOR RIGHTS, FROM THE PERSPECTIVE OF THE ASSOCIATE LAWYER, WITHIN THE LIMITS OF THE BAHIA SECTION.}

\begin{abstract}
:
The present study uses as its foundation a research carried out by the special commission of lawyers/associates of the section of the State of Bahia. It will also be analyzed whether the legal instruments that regulate the legal typology of the association contract are respected, whether the lawyers interviewed are subordinated, whether they are paid in accordance with the effective sharing of results, whether the maximum workload specified by the constitution is respected and whether receive remuneration in line with their professional practice. It was adopted, as a research method, the deductive and the qualitative reading through the research: "report of the special commission of lawyers/associates".
\end{abstract}

Key Words: Vulnerability; Protection; Labor Law; Associate Lawyer; precariousness

\section{INTRODUÇÃO}

\footnotetext{
* Advogado, formado pela Faculdade Católica de Salvador. Pós-Graduado em Direito do Trabalho pela Universidade de Coimbra. Mestrando em Direitos Fundamentais e Alteridade pela Universidade Católica do Salvador - Mestrado de Direito da UCSAL. E-mail: rafael.ribeiro.santos@ hotmail.com. Endereço Postal: Condominio Vog Ville Jocky Club, no endereço: Avenida Luis Tarquinio, 926, Centro, Lauro de Freitas-BA. CEP: 42700-130.

* Mestrando em Direitos Alteridade e Direitos Fundamentais, na área de concentração: Políticas públicas e efetivação de direitos fundamentais, pela Universidade Católica do Salvador, advogado, graduado em Direito pela Universidade Católica do Salvador. E-mail: eric.araujo.olveira@gmail.com. Endereço Postal: Condomínio Vilas do Joanes, Rodovia BA-99, Estrada do Coco, Km. 8, Catu de Abrantes, Camaçari- BA.
} 
Com a chegada dos anos 90, houve inúmeras mudanças nas políticas públicas Brasileiras, fato que expressa isso fora a insurgência da Lei n. 9.099/95 (BRASIL, 1995) disciplinando os Juizados Especiais e a Lei n. 8.078/90 (BRASIL, 1990) denominada Código de Defesa do Consumidor, microssistema processual primordialmente utilizado para tutelar lides de índole consumeristas.

Com isso a profissão da advocacia sofreu mudanças estruturais, as sociedades de advocacia inauguraram o formato de gestão de acordo com o dinamismo inerente às práticas de mercado e a expansão dos serviços jurídicos.

A reestruturação produtiva experimentada pelas sociedades de advocacia e a ampliação dos serviços jurídicos refletiram na contratação de advogados em larga escala, sob a égide da tipologia denominada de advogado associado. (GHIRARDI, 2014).

Esta nova forma de contratação como explicita o Regulamento Geral do Estatuto da Advocacia e da OAB em seu art.39 dispõe que a sociedade de advogados pode associar-se com advogados, sem vínculo de emprego, para participação nos resultados.

Em tese a contraprestação oriunda da participação dos resultados faz afastar os advogados de um possível vínculo empregatício, dando a eles autonomia e poder diretivo, tornando-o autônomo, além de consignar a percepção de honorários de acordo com a partilha efetiva dos resultados das causas e interesses que lhes foram confiados. E estas condições se fazem elementos condicionantes para que estas associações não infrinjam o RGEA.

Entretanto, a modalidade jurídica da associação, em alguns casos, tem sido mal utilizada, servindo como instrumento para dissimular relações empregatícias, desregulamentar o trabalho e permitir a precarização dos advogados contratados por esta modalidade. (COSTA JUNIOR, 2017).

O presente estudo não visa, contudo, efetuar críticas ou denunciar determinados escritórios que fazem uso de práticas ilegais, o mesmo tem o escopo de tornar evidente os possíveis abusos sofridos pelos jovens advogados e vislumbrar como é a realidade vivenciada por estes profissionais e se esta pratica está em comum acordo com os ditames acordados em suas "contratações " ou "associações ". Usando de uma pesquisa feita na seccional da OAB Bahia com cerca de 100(cem) advogados associados.

\section{O ADVOGADO ASSOCIADO}


No Regulamento Geral do Estatuto da Advocacia e da OAB o artigo 39 regula que a sociedade de advogados pode associar-se com advogados, sem vínculo de emprego, para participação nos resultados.

Ademais o Provimento 169/2015 do Conselho Federal da Ordem dos Advogados aduz também em seu art. $5^{\circ}$ entendimentos sobre esse tipo de parceria, proferindo que o profissional associado poderá participar de uma ou mais sociedades de advogados, mantendo sua autonomia profissional, sem subordinação ou controle de jornada e sem qualquer outro vinculo, inclusive empregatício.

Resta cristalino o entendimento que os advogados associados desempenham uma forma de trabalho ímpar. O presente estudo não tem a pretensão de tecer críticas aos advogados associados, muito menos aos grandes donos de escritórios. Sendo assim o artigo irá se restringir a analisar friamente os contratos de associações e como eles podem ser utilizados como forma de travestir uma relação comum de emprego.

De antemão se faz necessário a explanação da distinção entre relação de emprego e o regime adotado pelo advogado associado, para que assim uma futura ideia de precarização possa se perfazer.

É cediço que uma relação de trabalho é um termo bastante abrangente e genérico, abarcando algumas modalidades de contratação. Já a relação de emprego tem sua determinação alicerçada na Consolidação das Leis Trabalhistas (CLT), após verificada uma somatória de fatores. (PINHEIRO, TEIXEIRA, 2016).

Antes de adentrar especificamente na perspectiva trabalhista sobre a regulamentação
destes trabalhos, vale a pena lembrar quando se constitui o vínculo trabalhista.
Consoante a redação do artigo $3^{\circ}$, caput e parágrafo único, da Consolidação das Leis
do Trabalho, considera-se empregado toda pessoa física que prestar serviços de
natureza não eventual a empregador, sob dependência deste e mediante salário [...].
Não haverá distinções relativas a espécies de emprego e à condição de trabalhador,
nem entre o trabalho intelectual, técnico e manual (BRASIL; 1943). Deste
dispositivo, extrai-se não apenas os requisitos para configuração do vínculo de
emprego - pessoalidade, habitualidade, subordinação, oneroside - mas, também,
constata-se a existência de três formas de trabalho - intelectual, técnico e manual -
que podem ser executadas no contexto da relação empregatícia, ou fora dele.
(PINHEIRO, TEIXEIRA, 2016, p 41)

Os fatores que somados formalizam uma relação de emprego estão evidenciadas nos artigos $2^{\circ}$ e $3^{\circ}$ da CLT. São eles: prestação de serviços por pessoa física, com pessoalidade, não eventualidade, onerosidade e subordinação perante o empregador. 
Ainda neste contexto ao expressar a necessidade de que a prática laboral seja feita por pessoa física, anula a possibilidade de esta ser exercida por pessoa jurídica, e caso seja estaria desconfigurado a relação de emprego.

Entendido em seu contexto mais amplo, qualquer atividade laboral exige a capacidade intelectual do executor, isto é, exige que suas funções cerebrais operem no sentido de ativar o corpo para a feitura da atividade. (PINHEIRO, TEIXEIRA, 2016). De certo, as atividades exercidas por advogados são feitas por pessoas físicas, já que para a pratica das suas atividades laborais é necessário a inclusão na Ordem dos Advogados do Brasil, que só pode ser realizada por pessoa física.

No que tange o fator pessoalidade, a abordagem gira em torno da impossibilidade de substituição do prestador de serviço por outro, contrato "intuitu personae". Em outras palavras, pode-se dizer que o contrato de trabalho possui natureza intuito personae em relação ao empregado, e, por isso, este, necessariamente, deve consistir em pessoa certa e determinada, ressalvadas condições contratuais especialíssimas acerca de eventuais substituições (PINHEIRO, 2016 apud BARROS, 2004). Maurício Godinho Delgado acrescenta que:

Os bens jurídicos (e mesmo éticos) tutelados pelo Direito do Trabalho (vida, saúde, integridade moral, bem-estar, lazer, etc.) importam à pessoa física, não podendo ser usufruídos por pessoas jurídicas. Assim, a figura do trabalhador há de ser, sempre, uma pessoa natural [...] $\mathrm{O}$ fato de ser o trabalho prestado por pessoa física não significa, necessariamente, ser ele prestado com pessoalidade. Esse segundo elemento fático-jurídico tem, assim, que ser também aferido na relação jurídica concreta formulada entre as partes [...] É essencial à configuração da relação de emprego que a prestação do trabalho, pela pessoa natural, tenha efetivo caráter de infungibilidade, no que tange ao trabalhador (DELGADO, 2011).

Neste ponto existe algumas divergências. Em que pese os tribunais superiores entendam que a possibilidade de substituição de um advogado por outro que integrem o mesmo escritório não descaracteriza este elemento, há quem pense o contrário. Usando como base o Código de Ética, art. 11, que trata da especificidade das procurações existe a possibilidade de o advogado ser substituído por outro na prestação de determinado serviço.

A não eventualidade retrata a necessidade de habitualidade, afastando a ideia de trabalhos esporádicos ou pontuais. Consoante salienta Elaine Ribeiro do Prado, enquanto característica essencial à configuração da relação empregatícia, a eventualidade pressupõe que a relação entre empregador e empregado contará com uma prestação de serviços por parte 
deste, de forma sucessiva e permanente, ainda que as jornadas de trabalho sejam fixadas em dias alternados, ou o limite de horas seja inferior ao legal (PRADO, 2011).

No que tange a habitualidade, é claro que o advogado associado precisa, em algum momento, estar presente no escritório que trabalha, seja para lidar com o sistema específico de cada cliente, com os arquivos salvos no computador da empresa e até mesmo para trocar ideias com os demais associados. No entanto, isto por si só não caracteriza habitualidade, uma vez que a sua falta, por exemplo, não precisa ser justificada e não há sequer controle de ponto para medir essa presença. Na doutrina de Maurício Godinho Delgado, resta constatado que:

\begin{abstract}
A ideia de permanência atua no Direito do Trabalho em duas dimensões principais: de um lado, na duração do contrato empregatício, que tende a ser incentivada ao máximo pelas normas jus trabalhistas. Rege esse ramo jurídico, nesse aspecto, o princípio da continuidade da relação de emprego, pelo qual se incentiva, normativamente, a permanência indefinida do vínculo de emprego, emergindo como exceções as hipóteses de pactuações temporalmente delimitadas de contratos de trabalho. De outro lado, a ideia de permanência vigora no Direito do Trabalho no próprio instante da configuração do tipo legal da relação empregatícia. Através do elemento fático-jurídico da não eventualidade, o ramo jus trabalhista esclarece que a noção de permanência também é relevante à formação sociojurídica da categoria básica que responde por sua origem e desenvolvimento (a relação de emprego) (DELGADO, 2011).
\end{abstract}

É natural, no entanto, que o titular do escritório exija um mínimo de comparecimento e dedicação constante a uma atividade de trabalho, pois caso contrário o advogado estaria trabalhando sozinho e não associado a uma empresa e se beneficiando de toda a estrutura, física e intelectual, que ela oferece. Há que se falar ainda que se ele trabalha em um escritório, mas realiza todo o trabalho em casa, adentra-se nova modalidade de labor, o teletrabalho, que possui um conjunto de regulamentações próprias.

Quem melhor conceitua esta modalidade é Fincato (2011) explicitando que o teletrabalho é a modalidade de trabalho, a partir da qual alguém presta serviços por meio das ferramentas de comunicação e informação (notoriamente por meio da internet), distante geograficamente do seu tomador de serviços.

O fator "onerosidade" se refere a remuneração quitada pelo empregador em favor do empregado, em decorrência do trabalho prestado, afastando a ideia de trabalho voluntario ou “favor". Salvo nos casos regulamentados pelo Código de Ética em seu Capitulo V, da advocacia pro bono, quem em seu art. $30^{\circ}, \S 1^{\circ}$ expressa que "considera-se advocacia pro bono a prestação gratuita, eventual e voluntaria de serviços jurídicos em favor de instituições 
sociais sem fins econômicos e aos seus assistidos, sempre que os beneficiários não dispuserem de recursos para a contratação de profissionais “.

Por fim, vem o fator "subordinação", originalmente classificado pela necessidade que o empregado tem em respeitar as ordens oriundas de seu empregador ou da empresa, ou seja, a dependência hierárquica entre a submissão da atividade laboral prestada pelo empregado em favor do empregador.

O tema subordinação é bastante controverso. Uma vez que os elementos caracterizadores do vínculo devem estar presentes de forma cumulativa, ainda que os acima elencados se concretizem, a subordinação será determinante para a existência ou não da relação de emprego. Segundo Maurício Godinho Delgado:

A subordinação corresponde ao polo antitético e combinado do poder de direção existente no contexto da relação de emprego. Consiste, assim, na situação jurídica derivada do contrato de trabalho, pela qual o empregado compromete-se a acolher o poder de direção empresarial no modo de realização de sua prestação de serviços (DELGADO, 2011).

Com relação à sua natureza jurídica, a subordinação pode se apresentar por meio de quatro aspectos distintos (subordinação jurídica ou dependência hierárquica, dependência econômica, dependência técnica, e dependência social), contudo, a doutrina majoritária entende que, para a constatação do trabalho subordinado, o critério que melhor se adequa é o da subordinação jurídica, de forma objetiva. Ainda assim, a doutrina não é pacífica, (PINHEIRO, TEIXEIRA, 2016). Consoante Reginaldo Melhado:

É flagrantemente falso supor que uma relação de subordinação jurídica possa ser
concebida como fato objetivo; ela é, ao revés, uma relação sempre subjetiva.
Ninguém pode exercer sobre outrem um poder de sujeição desprovido do elemento
subjetivo que tal conduta requer. Sem intencionalidade não se cometem atos de
autoridade. E o poder tem outra face, uma face oposta de mesma natureza: a
submissão, que é em si mesma uma situação objetiva, de índole decisória. Salvo por
coação (ou algum outro vício), o sujeito passivo da relação de poder decide sujeitar-
se a uma ordem. Faz isso racionalmente - em muitos casos, talvez, por não dispor de
outra alternativa, como quando busca sua subsistência material, por exemplo -, mas
essa é a racionalidade possível e muito próxima do capitalismo. Até porque, diante
do contrato, o trabalhador é um ser isolado, uma individualidade distante de sua
classe social" (MELHADO, 2003).
o advogado, mesmo atuando como associado em um escritório,

É certo que o advogado, mesmo atuando como associado em um escritório, trabalha segundo seu modo de agir e sua convicção, pois é ele diretamente que elabora suas peças, que se faz presente em audiências, que lida com os clientes e que cria teses de defesa ou de ataque. 
O escritório de advocacia, no entanto, é uma empresa e não há como subsistir sem que algumas regras sejam seguidas. Sendo assim, qualquer advogado a ele associado deve atuar nos conformes dos princípios e diretrizes estabelecidos. Caso contrário, mais uma vez, escolheria optaria por ser autônomo, mas assim não o fez porque ciente de que se beneficiaria do que o escritório tem a oferecer. Alice Monteiro de Barros acrescenta, ainda, que:

\begin{abstract}
Se, ainda assim, os trabalhos intelectuais estiverem sujeitos à rotulação como trabalhos autônomos, pode-se adotar os requisitos propostos pela doutrina italiana, se a atividade laboral poderá ser objeto do contrato de trabalho, independentemente do resultado dela consequente; se a atividade prevalentemente pessoal é executada com instrumentos de trabalho e matéria-prima da empresa; se a empresa assume substancialmente os riscos do negócio; se a retribuição é fixada em razão do tempo do trabalho subordinado, pois se ela é comensurada em função do resultado da atividade produtiva, tende à subsistência de um trabalho autônomo, embora essa forma de retribuição seja compatível com o trabalho a domicílio subordinado, o mesmo ocorrendo se a prestação de serviço é de caráter contínuo (BARROS, 2004).
\end{abstract}

Frise-se que este fator organizacional é importante principalmente para o advogado associado, eis que quanto mais estruturada e coordenada é uma empresa, mais confiável perante seus clientes e maior a sua carteira, o que significa um maior reconhecimento e contraprestação para o próprio associado que lá trabalha.

Dessa forma, ao optar por laborar não como autônomo, mas como associado a um escritório de advocacia, o advogado aceita se submeter a algumas regras, mas, em contrapartida, recebe inúmeros benefícios, inclusive clientes que não teria se trabalhasse por conta própria.

\title{
2.1 Advogados associados e escritório de contencioso de massa
}

Notoriamente com a chegada dos anos 90, houve inúmeras mudanças nas políticas públicas Brasileiras, fato que expressa isso fora a insurgência da Lei n. 9.099/95 (BRASIL, 1995) disciplinando os Juizados Especiais e a Lei n. 8.078/90(BRASIL, 1990) denominada Código de Defesa do Consumidor. Microssistema processual primordialmente utilizado para tutelar lides de índole consumeristas.

Desta forma, o crescimento das relações consumeristas, regido agora por regulamento especial, repercutiu numa grande procura pela tutela jurisprudencial. Regido primordialmente em lides de pequena complexidade. Segundo Roque (2002):

O Brasil reúne mais faculdades de direito que China, Estados Unidos da América e Europa juntos. Segundo o Conselho Federal da OAB, há, atualmente, 1.197.483 
advogados em todo país, o que representa uma proporção estimada de um advogado para cada 190 habitantes. Evidente, pois, que essa enorme quantidade de profissionais acaba por impactar no aumento do número de demandas ajuizadas, lembrando que a cada semestre são formados novos profissionais pelas universidades. (Roque, 2020, p. 59).

Fato este que reverberou na facilitação do acesso à justiça perante os Juizados Especiais de Defesa do Consumidor. Isto desaguou em um aumento considerável das demandas desta natureza, por conseguinte, criando um novo e vasto mercado para a atuação da advocacia. Camargo (2012), também aduz que:

Várias são as características do contencioso de consumo no Brasil: em primeiro lugar, o fato de os JECs serem gratuitos e o valor de alçada ser de até 40 salários mínimos, permite que a integralidade dos bens mais desejados pela nova classe média (celular, laptop, TVs de tela plana, geladeira, máquina de lavar, cartão de crédito, empréstimo pessoal, telefonia, TV por assinatura etc.) Possam ser discutidos nessa instância. (CAMARGO, 2012, p.13).

Essas inúmeras transformações instigaram que os escritórios de advocacia sofressem uma restruturação produtiva, abandonado o formato clássico e artesanal para ingressar no mundo empresarial, se tornando verdadeiras corporações, priorizando a celeridade, lucro e quantidade.

A massificação do mercado consumidor brasileiro intensificou a "judicialização" destas causas, consoante denunciam os dados colhidos. A investigação não pretende debater o mérito do acesso à justiça ou a beligerância social, muito menos aprofundar nos procedimentos jurídicos adotados, mas apenas constatar a majoração dos litígios que se desenvolve perante os juizados, ampliando o mercado para a atuação dos escritórios de advocacia. (JUNIOR, 2016.p.56).

Esta mudança só pode acontecer pois, com o surgimento deste novo segmento da advocacia, os Juizados Especiais, o número de processos era absurdamente alto, foçando que os advogados agora não mais prezassem por uma advocacia mais especialista e detalhista, já que as causas que versavam sobre essa lide eram em sua grande maioria de baixa complexidade.

Porém uma grande problemática se insurgia, o que antigamente a advocacia prezava por poucos advogados competentes e especializados, agora se glorificava por uma "advocacia de massa" aonde o foco principal é angariar o máximo de clientes possíveis e ter o maior número de advogados para conseguir adimplir a demanda estrondosa.

Isso abriu espaço para inúmeras contratações ou associações, já que não eram mais necessários advogados experientes, mas sim advogados capazes de adimplir as demandas agora exigidas. Entretanto Júnior (2016) salienta que causas de até 20 salários mínimo nos juizados especiais, dispensam a atuação do advogado. 
Em suma, o aquecimento do mercado e a proposta flexível de avançar o processo de cumulação para o setor de serviços encontrou na advocacia um reduto lucrativo com potencial inexplorado. Modificando a morfologia dos escritórios que abandonaram o formato tradicional para ingressar no ramo da advocacia coorporativa, transformando-se em verdadeiras empresas.

O Superior Tribunal de Justiça, ainda que de forma mitigada, intensificou essa "desproteção" ao negar a possibilidade de proteção jurídica das petições como objeto de direito autoral. Nas palavras do Relator, "por seu caráter utilitário, a petição inicial somente estará protegida pela legislação se constituir criação literária, fato negada pelas instâncias ordinárias. Súmula 7/STJ. Recurso não conhecido" (STJ, 2002. apud PINHEIRO, TEIXEIRA, 2016).

\section{RELATÓRIO DA COMISSÃO ESPECIAL DOS ADVOGADOS/AS ASSOCIADOS DA OAB-BA}

Inicialmente, importa ressaltar que não se trata de pesquisa definitiva, mas de indícios preliminares para formular uma proposta ao Conselho Seccional da OAB-BA e uma análise preambular de como se desenvolve o vínculo entre as sociedades de advocacia e os advogados associados.

A pesquisa preliminar foi realizada através de um questionário estruturado com 45 (quarenta e cinco) perguntas através de um questionário eletrônico que fora disponibilizado entre as ferramentas do sistema Google, ficando aberto para respostas entre 12/06/2019 15/06/2019, até atingir a amostra de 100 (cem) entrevistados.

As indagações consideraram a jurisprudência e a doutrina que se debruçam sobre os fenômenos que ladeiam a relação jurídica denominada de associação, constituída entre advogados e sociedades de advocacia.

Sem mais delongas, como fora explicitado em outros tópicos, é de suma importância antes da explicitação dos dados contidos nesta pesquisa, que o estudo consolidasse a ideia central dos liames que versam as relações entre os advogados associados e suas associações. Caracterizando-o como uma relação não laboral e totalmente alheia aos artigos $2^{\circ}$ e $3^{\circ}$ da CLT. 
Com o intuito de enfatizar esse distanciamento se faz necessário que o questionamento se alicerce primordialmente nos quatro principais norteadores de uma relação de emprego. Com o intuito meramente ilustrativo norteia o art. $5^{\circ}$ do Provimento 169/2015 do CFOAB:

Art. $5^{\circ} \mathrm{O}$ advogado associado, na forma do art. 39 do Regulamento Geral do Estatuto da Advocacia e da $\mathrm{OAB}$, poderá participar de uma ou mais sociedades de advogados, mantendo sua autonomia profissional, sem subordinação ou controle de jornada e sem qualquer outro vínculo, inclusive empregatício, firmando para tanto contrato de associação que deverá ser averbado no Registro de Sociedades de Advogados perante o respectivo Conselho Seccional. (CFOAB, art. $5^{\circ}$ do provimento 169/2015)

Sendo assim o questionário formulou perguntas a fim de identificar se existe qualquer tipo de poder diretivo agindo nesta relação. Os resultados apontaram que 93\% responderam que estão subordinados a alguém no escritório; $47 \%$ têm jornadas determinadas pelo escritório; $71 \%$ não influenciam nas decisões gerenciais do escritório e $10 \%$ influenciam apenas nos clientes que conseguem prospectar.

Não fugindo ainda do explicitado no art. $5^{\circ}$ do Provimento 169/2015 do CFOAB colacionado alhures, mais perguntas que tangenciam o mesmo foram feitas, os resultados mostram que $38 \%$ das petições passam por revisão de outro advogado; $36 \%$ responderam que, às vezes a peça passa pela revisão de outro advogado; $39 \%$ não assinam as petições que realizam; $40 \%$ trabalham com metas; $72 \%$ trabalham com modelo de petição préestabelecido; $42 \%$ narraram que apenas às vezes tem liberdade para alterar as petições; $12 \%$ não tem liberdade para alterar as petições; $61 \%$ não acreditam que o vínculo estabelecido com o escritório corresponde com a realidade e $23 \%$ não souberam informar.

De prima face, alguns dados colacionados são bastantes expressivos, e merecem destaque, são eles o montante de $93 \%$ dos entrevistados que identificaram o elemento da subordinação em seu vínculo com a sociedade de advogados, bem como $61 \%$ que asseveraram que a associação estabelecida não corresponde com a sociedade.

A segunda parte da pesquisa versa sobre a participação nos resultados, inerente a relação jurídica do associado, expressamente contido no Art. 39 do Regulamento Geral do Estatuto da Advocacia e da OAB " A sociedade de advogados pode associar-se com advogados, sem vínculo de emprego, para participação nos resultados”. Neste aspecto algumas considerações se fazem necessárias. 
Logicamente que o advogado associado não irá fazer jus à determinada porcentagem do lucro provindo de determinado escritório, pois isto abarcaria uma problemática muitas vezes impossível de ser solucionada, com o finco de minimizar este problema o art. $7^{\circ}$ também do o Provimento 169/2015 do Conselho Federal da Ordem dos Advogados aduz que serão de direito os honorários contratados por determinado cliente resultantes ás causas e interesses que lhe forem confiados.

Destarte, considerando o que fora exposto o questionário agora formulou perguntas a fim de verificar se os entrevistados recebem honorários objetivamente vinculados a participação nos resultados nas causas e interesses que lhe forem confiados, conjunta ou isoladamente, o resultado fora que $68 \%$ recebem valores fixos. $24 \%$ fixos mais variável e $8 \%$ variável; $32 \%$ narraram que os valores recebidos não têm vinculação aos contratos em que trabalham. $42 \%$ sequer conhecem os contratos firmados entre o escritório e os clientes; $86 \%$ não recebem participação em honorários de sucumbência.

De forma dedutiva é possível perceber que de acordo com os dados colhidos que os contratos de associação firmados entre advogados e sociedade de advocacia, em sua grande maioria dos entrevistados não observam os critérios estabelecidos pelas normas que regulam esta relação jurídica, não obstante disto evidenciou também que os aludidos profissionais sequer conhecem os contratos firmados entre os escritórios e os clientes, tornando impossível a verificação se os honorários estão de acordo com a partilha real dos resultados.

Já o ponto três da pesquisa gira em torno da averbação do contrato de associação na Seccional da Ordem dos Advogados do Brasil, fato este que estar redigido de forma cristalina no parágrafo único do Art. 39 do Regulamento Geral do Estatuto da Advocacia e da Ordem dos Advogados do Brasil e o Art. 5 do Provimento n. 169/2015 do Conselho Federal da Ordem dos Advogados do Brasil, afirmando que o contrato de associação deverá ser averbado no Registro de Sociedades de Advogados perante o respectivo Conselho Seccional.

Art. 39. A sociedade de advogados pode associar-se com advogados, sem vínculo de emprego, para participação nos resultados. Parágrafo único. Os contratos referidos neste artigo são averbados no registro da sociedade de advogados. (CFOAB, art. 39 do Provimento n. 169/2015) Art. 5 O advogado associado, na forma do art. 39 do Regulamento Geral do Estatuto da Advocacia e da OAB, poderá participar de uma ou mais sociedades de advogados, mantendo sua autonomia profissional, sem subordinação ou controle de jornada e sem qualquer outro vínculo, inclusive empregatício, firmando para tanto contrato de associação que deverá ser averbado 
no Registro de Sociedades de Advogados perante o respectivo Conselho Seccional. (CFOAB, art. $5^{\circ}$ do Provimento n. 169/2015)

De forma que essa exigência pelos instrumentos normativos está alinhada com a função fiscalizatória que deve ser desempenhada quando do registro do contrato de associação perante a respectiva seccional, pois, como assevera o Art. $9^{\circ}$ do Provimento n. 169/2015 que não será admitida a averbação do contrato de associação que contenha, em conjunto, os elementos caracterizadores de relação de emprego. Ou seja, de forma logica, é imperiosa a necessidade de que os registros derivados dessas associações sejam registrados, pois só assim poderão ser feitas as devidas fiscalizações e salvaguardar os direitos destes profissionais.

Diante do requisito formal exigido pelas normas pertinentes, o questionário perguntou aos entrevistados se possuem contrato de associação com as sociedades de advogados averbado na Ordem dos Advogados do Brasil, Seccional Bahia. $66 \%$ dos advogados responderam que o contrato não está registrado no aludido órgão.

A ausência de formalização do contrato perante a OAB implica em inobservância dos preceitos normativos que regulam a relação jurídica do associado, desrespeitando um dos elementos de validade do negócio jurídico, conforme estipula o Art. 104 do Código Civil.

Com o conglomerado de informações explicitadas até então, a pesquisa se restringiu a formular perguntas meramente relacionadas aos requisitos normativos que regulam e alicerceiam a relação jurídica da associação entre advogados e escritórios. Porém de forma supletiva, a pesquisa optou por fazer perguntas que vão além destes pré-requisitos, perguntas estas que visam enriquecer o presente estudo.

Uma destas perguntas supletivas referem-se ao montante percebido por estes advogados nos moldes de associados quanto a remuneração mensal, os resultados mostraram que $8 \%$ recebem até $\mathrm{R} \$ 1.200,00$ por mês; $31 \%$ recebem de $\mathrm{R} \$ 1.201,00$ até $\mathrm{R} \$ 2.000,00$ por mês; 39\% recebem de $\mathrm{R} \$ 2.001,00$ até $\mathrm{R} \$ 3.000,00$ por mês; $13 \%$ recebem de $\mathrm{R} \$ 3.001,00$ até $\mathrm{R} \$ 4.000,00$ por mês; $9 \%$ recebem mais de R $\$ 4.000,00$ por mês; $56 \%$ dos entrevistados complementam a renda de outra maneira.

Digno de notar que $78 \%$ dos entrevistados recebem remuneração mensal inferior ao piso estipulado para advocacia de $\mathrm{R} \$ 3.500,00$ (três mil e quinhentos reais), aprovado pelo Conselho Seccional da OAB/BA no ano de 2015 (OAB, 2015).

Outra pergunta supletiva que é digna de atenção é aquela que investiga a carga 
horária de labor destes profissionais. Os resultados foram que $8 \%$ trabalham até $4 \mathrm{~h}$, por dia; $36 \%$ trabalham entre $5 \mathrm{~h}$ e $8 \mathrm{~h}$, por dia; $56 \%$ trabalham mais do que $8 \mathrm{~h}$, por dia; $47 \%$ trabalham durante os finais de semana; $53 \%$ não trabalham durante o final de semana.

Sendo assim, os dados demonstram que os entrevistados apresentaram um prolongamento exacerbado de horas de trabalho, pois $56 \%$ laboram mais do que $8 \mathrm{~h}$ por dia, bem como $47 \%$ estendem suas atividades para os finais de semana.

Por último, mas não menos importante a pesquisa levou em consideração a saúde mental dos profissionais que laboram sobre esses ditames, separadamente em mais três formas de questionamentos, a frustação com a advocacia, doenças psiquiátricas/psicológicas ocupacional e violência simbólica.

De certo estes três últimos questionamentos que a pesquisa evidencia pouco influenciam no estudo em questão, porém os resultados foram tão expressivos que conseguiram galgar um lugar de relevância em detrimento as demais informações. De forma respectiva, os resultados em relação a frustação com a advocacia são que $61 \%$ dos entrevistados não estão submetidos à plano de carreira; $70 \%$ não pensam em fazer carreira na sociedade de advocacia do qual são associados; $57 \%$ permanecem até 2 anos na sociedade de advogados; $50 \%$ estão extremamente insatisfeitos com o trabalho; $83 \%$ pensaram em abandonar a advocacia.

A constatação que mais chama atenção é a considerável quantidade de entrevistados que cogitaram abandonar a advocacia. Observa-se que $83 \%$ dos advogados que responderam ao questionário, em algum momento, pensaram em deixar a profissão.

No que tange a doenças psíquicas/psicológicas ocupacional o resultado é que 55\% já enfrentou algum problema de ordem psicológica e/ou psiquiátrica em razão do trabalho que exerce no escritório de advocacia.

Já no que tange a violência simbólica, fica evidenciado que $69 \%$ dos entrevistados tem medo de buscar os órgãos de fiscalização

\section{UMA POSSIVEL PRECARIZAÇÃO DOS DIREITOS TRABALHISTAS}

Resta nítido que as hipóteses levantadas pela pesquisa preliminar versam sobre a possibilidade de a relação jurídica dos advogados não respeitar os elementos previstos nas normas regulamentadoras da matéria. E consoante se verifica na análise dos dados já 
explicitados em tópicos anteriores, que existe uma possível violação dos requisitos constitutivos da figura jurídica de uma associação genuína.

Ainda nesta esteira, e tomando como alicerce os resultados apresentados nas pesquisas apresentadas, resta cristalino o entendimento de que os profissionais em sua grande maioria, laboram sobre uma constante subordinação. Seja ela por um "software" no qual a empresa utiliza, seja por um advogado hierarquicamente mais antigo no escritório ou por qualquer outra pessoa que passe a fiscalizar ou corrigir todas as ações promovidas pelos profissionais que laboram sobre esses ditames.

No que tange a carga horaria não eventual na qual o associado deveria ser submetido, fora percebido que a mesma é totalmente desmembrada pela quantidade incessante de processos nos quais cada advogado associado tem a necessidade de adimplir. Forçando o mesmo, a eventualmente exceder as 44 (quarenta e quatro) horas semanais de labor.

Assim como tampouco fora evidenciado que os advogados não participam efetivamente da partilha dos resultados, assim como muitas vezes desconhecem o contrato de prima face.

Não obstante todos os absurdos nos quais a pesquisa torna público, resta evidente que paralelo todas estas informações, os advogados associados, em grande maioria, sequer tiveram seus contratos de associação averbados perante a Ordem dos Advogados do Brasil. O que leva a qualquer pessoa a questionar, qual aberração laboral estes profissionais então sujeitos? Estes estão sendo privados de direitos fundamentais ofertados e protegidos pela Carta Magna? Quais a medidas cabíveis para a solução desta aberração?

Ao passo que uma caracterização desta relação se distancia, esta evidencia somente os pontos que tornam cristalino uma crescente precarização, como precede:

Em geral, elas visam: 1) ampliar a adoção de contratos atípicos e rebaixar direitos do contrato padrão; 2) flexibilizar a utilização do tempo de trabalho; 3) alterar as regras de remuneração do trabalho, especialmente em relação às formas de pagamento (mais variáveis) e à política do salário mínimo; 4) fragilizar as regras de segurança e saúde do trabalho; 5) enfraquecer a atuação pública na fiscalização do respeito à legislação trabalhista; 6) descentralizar a definição das normas e redefinir o papel dos sindicatos. Em síntese, a tendência é a busca de um padrão de regulação do trabalho menos protetivo, propiciando maior liberdade de determinação, pelo empregador, das condições de contratação, uso e remuneração da força de trabalho (KREIN; OLIVEIRA; FILGUEIRAS, 2019, p. 226). 
Estas são perguntas nas quais o estudo se propôs a discutir, haja vista que até a presente data não existe nenhuma regulamentação dos órgãos superiores que normatize e regule o que está acontecendo com estes profissionais.

O que é notório e perceptível, é que alguns profissionais insatisfeitos com essa conduta estão procurando seus direitos perante a justiça do trabalho, algumas vezes obtendo êxito e outras vezes não.

Mais uma vez com o intuito de elucidar o que propõe o estudo, o processo de $n$. 10.2014.5.06.0005, com sentença proferida pelo O juiz do Trabalho, Hélio Luiz Fernando Galvão, da $5^{\mathrm{a}}$ vara de Recife/PE, entendeu que:

\begin{abstract}
No sentido de que ele, a partir do instante em que for intimado desta decisão, se abstenha de contratar advogado como associado, quando presentes os pressupostos caracterizadores de relação de emprego, nos termos do segundo e do terceiro artigos da CLT, sendo advertido de que, caso descumpra esta ordem judicial, estará sujeito ao pagamento de multa no importe de $\mathrm{R} \$ 20.000,00$ (vinte mil reais) e, ainda, ao pagamento de multa no importe de $\mathrm{R} \$ 10.000,00$ (dez mil reais) por cada trabalhador prejudicado, ambas reversíveis ao FAT.
\end{abstract}

Porém, no agravo de instrumento em recurso de revista interposto perante a $6^{\circ}$ turma do TST de n. 47601-61.2008.5.01.0036 com Ministro relator do processo, Aloysio Corrêa da Veiga, considerou que, conforme o TRT-RJ, a reclamação da advogada não poderia prosperar, uma vez que dentre as exigências que configuram o vínculo de emprego, como a pessoalidade, a habitualidade, a onerosidade e a subordinação, restava em falta a última, a subordinação jurídica, tida como requisito essencial para o reconhecimento do direito pleiteado.

Sendo assim e na falta de uma normatização, é imperioso que cada processo seja analisado perante o princípio norteador da justiça do trabalho, a primazia da realidade. $\mathrm{O}$ que não afasta a necessidade de uma vasta discussão sobre o tema em questão.

\title{
5 CONCLUSÃO
}

Os resultados preliminares do relatório demonstraram que, em regra, os instrumentos jurídicos que regulamentam a tipologia jurídica do contrato de associação não são respeitados. Os advogados sofrem subordinação, não recebem de acordo com a efetiva partilha de resultados, trabalham em jornadas extensas e recebem baixa contraprestação remuneratória. Além disso, identificou-se, prefacialmente, que as sociedades de advogados, em regra, não 
averbam os contratos de associação perante a OAB. Assim também entende Santos, Petersen Teixeira Almeida (2019):

Pelo exposto, conclui-se que a proletarização do advogado no Brasil tem a mão-deobra barata como grande contribuição para que isso ocorra por conta da grande oferta de advogados no mercado de trabalho, excessivo número de litigância, dificuldade de fiscalização nos escritórios, entre outros. Sendo assim, o problema deve ser tratado como social. Por fim, foi necessário refletir sobre uma proposta de mudança que tenha punição e repercussão ética a qual resultou na ideia de criação do selo OAB. Assim, os escritórios que cumprirem seus contratos de maneira coerente e correta recebem tal selo como mérito trazendo respaldo e credibilidade para aquela sociedade advocatícia. (SANTOS, 2019, p. 19)

Neste multiverso da advocacia de massa está implícito a precarização estrutural do trabalho em todas as suas dimensões, haja vista que esta é a intenção. Travestindo uma associação legal em uma relação laboral nefasta, flexibilizando o tempo de trabalho, mancomunando uma falsa ideia de remuneração, afastando qualquer ideia de segurança e saúde do trabalho e obstaculizando qualquer ilusão de fiscalização.

Em consequência da elevada precarização incidente no contencioso de massa, o jovem advogado, que constituí a força de trabalho mais numerosa neste modelo daninho, acaba por reverberar na decepção com a carreira jurídica. Fazendo com que tendem a buscar outras oportunidades de labor, que ofertem o mínimo de dignidade.

É possível caracterizar essa situação como uma aberração jurídica, pois aqueles que deveriam estar pleiteando a proteção e salvaguardando os direitos alheios acabam por deixar os seus próprios de lado, sob a esperançar de poder iniciar sua carreira jurídica. E pior, toda esta hermenêutica jurídica empresarial é explicita, ao ponto de os grandes donos de escritórios de contencioso de massa acharam que ao "contratarem" um advogado nesses ditames estariam não usurpando sua força de trabalho, mas sim prestando uma grande ajuda ao jovem advogado, por ofertar a primeira oportunidade de labor.

\section{REFERENCIAS:}

BARROS, Alice Monteiro de. Trabalhadores intelectuais. Revista do Tribunal Regional do Trabalho 3a Região. Belo Horizonte, v. 39, n. 69, jan./jun. 2004.

BRASIL. Lei No 9.099, De 26 De Setembro De 1995. Dispõe sobre os Juizados Especiais Cíveis e Criminais e dá outras providências. Disponível em: <http://www.planalto.gov.br/ccivil_03/leis/19099.htm\#: :text=LEI\%20N\%C2\%BA\%209.099 
\%2C\%20DE\%2026\%20DE\%20SETEMBRO\%20DE\%201995.\&text=Disp\%C3\%B5e\%20so bre $\% 20$ os $\% 20 J u i z a d o s \% 20$ Especiais $\% 20 \mathrm{C} \% \mathrm{C} 3 \%$ ADveis $\% 20 \mathrm{e} \% 20 \mathrm{Criminais} \% 20 \mathrm{e} \% 20 \mathrm{~d} \% \mathrm{C}$ 3\%A1\%20outras\%20provid\%C3\%AAncias. Acesso em: 20 de maio de 2020>.

BRASIL. lei $N^{\circ}$ 8.078, De 11 De Setembro De 1990. Dispõe sobre a proteção do consumidor e dá outras providências. Disponível em: http://www.planalto.gov.br/ccivil_03/leis/18078.htm. Acesso em: 20 de maio de 2020

BRASIL. Tribunal Regional do Trabalho da $6^{\mathbf{a}}$ Região. Sentença trabalhista na Reclamação Trabalhista n. 47601-61.2008.5.01.0036. Ministro relator do processo, Aloysio Corrêa da Veiga.

BRASIL. Vara do Trabalho da $6^{0}$ região. Sentença trabalhista na Reclamação Trabalhista $\mathrm{n}^{\mathrm{o}}$ 0000801-79.2017.5.05.0025. O juiz do Trabalho, Hélio Luiz Fernando Galvão, da $5^{\mathrm{a}}$ vara de Recife/PE.

CARELLI, Rodrigo. O Abuso De Direito e Fraude Trabalhista Na Contratação De Advogados Como Sócios e Associados Em Escritórios De Advocacia. Artigos, Ensaios e Direito Do Trabalho. 2017. Blog no WordPress. Disponível em: $<$ https://bomfimadvogados.com.br/o-abuso-de-direito-e-fraude-trabalhista-na-contratacao-deadvogados-como-socios-e-associados-em-escritorios-de-advocacia/>. Acesso em: 06 jul. 2021.

CAMARGO, S. Administração Eficiente e Consumo. Legislação e Tributos, Valor Econômico. São Paulo, 2012.

CONSELHO FEDERAL DA ORDEM DOS ADVOGADOS. RESOLUÇÃO N. 02/2015. Disponível em: <https://www.oab.org.br/arquivos/resolucao-n-022015-ced2030601765.pdf>. Acesso em 1 de maio de 2020.

CONSELHO FEDERAL DA ORDEM DOS ADVOGADOS. Provimento 169/2015. Disponível em: https://www.oab.org.br/leisnormas/legislacao/provimentos/169-2015. Acesso em 1 de maio de 2020.

COSTA JUNIOR. Os jovens operários da advocacia. Capitulo 3,CRV, 2017. 
DELGADO, Maurício Godinho. Curso de Direito do Trabalho. 10 ed. São Paulo: LTr, 2011.

PRADO, Elaine Ribeiro do. Gestão e justiça no trabalho inovador - o direito do trabalho na propriedade intelectual. Rio de Janeiro: Lumem Juris, 2011.

GHIRARDI, J. G. O mercado da advocacia em um mundo em transformação. In: A Formação da Advocacia Contemporânea. Rio de Janeiro: Fundação Getúlio Vargas, 2014.

JUNIOR, Vander Luiz Pereira Costa. Os jovens operários da advocacia: um estudo sobre a precarização do trabalho nos escritórios de contencioso de massa. Bahia: UCSAL, 2016

KREIN, José Dari; OLIVEIRA, Roberto Véras de; FILGUEIRAS, Vitor Araújo. As Reformas Trabalhistas: promessas e impactos na vida de quem trabalha. Cad. CRH, Salvador, v. 32, n. 86, p. 225-229, ago. 2019. Disponível em: <http://www.scielo.br/ scielo.php? script=sci_arttext \&pid=S0103-49792019000200225\&lng=pt\&nrm=isso>. Acesso em 28 out. 2019.

MELHADO, Reginaldo. Poder e Sujeição: os fundamentos da relação de poder entre capital e trabalho e o conceito de subordinação. São Paulo: LTr, 2003.

ORDEM DOS ADVOGADOS DO BRASIL. Regulamento Geral do Estatuto da Advocacia e da OAB, 1994. Disponível em

<http://www.oab.org.br/Content/pdf/LegislacaoOab/RegulamentoGeral.pdf> Acesso em $1^{\circ}$ de maio de 2020.

PRADO, Elaine Ribeiro do. Gestão e Justiça No Trabalho Inovador: o Direito Do Trabalho Na Propriedade Intelectual. Rio de Janeiro: Lumem Juris, 2011.

ROQUE, Andre Vasconcelos. Inteligência artificial na tomada de decisões judiciais: três premissas básicas. Rio de Janeiro: REDP, 2020

SANTOS, Petersen Teixeira Almeida. O advogado associado: a proletarização da advocacia e a recorrente fraude contratual. Disponível em: <http://ri.ucsal.br:8080/jspui/bitstream/prefix/904/1/TCCCLARASANTOS.pdf. Acesso em: 06 jul. 2021>. 
